\title{
Highlighting the immunohistochemical profile of melanocytomas (Review)
}

\author{
PASCALE QUATRESOOZ, CLAUDINE PIÉRARD-FRANCHIMONT and GÉRALD E. PIÉRARD
}

\author{
Department of Dermatopathology, University Hospital of Liège, Liège, Belgium
}

Received November 15, 2007; Accepted February 22, 2008

\begin{abstract}
The histological assessment of atypical melanocytic neoplasms is mandatory to ensure proper diagnosis and treatment. However, for some atypical lesions, expert pathologists report only moderate concordance in the diagnosis. In addition, certain atypical neoplasms have been coined differently in the literature. These designations include among others atypical and metastasizing Spitz tumor, malignant Spitz naevus, borderline and intermediate melanocytic tumor, and melanocytic tumor of uncertain malignant potential (MELTUMP) or Spitzoid melanocytic tumor of uncertain malignant potential (STUMP). These neoplasms are grouped here under the heading melanocytoma. Such melanocytic lesions have a benign outcome but exhibit an atypical and worrisome aspect. Rare individual cases of melanocytomas can progress to locoregional disease (agminate melanocytomas), and even beyond. At times, the distinction between melanocytoma and melanoma is difficult and may even be impossible. However, multipronged immunohistochemistry can help define malignancy risk stratification and therapeutic guidelines.
\end{abstract}

\section{Contents}

1. Introduction

2. Definition of melanocytoma

3. Uncertainties about melanocytomas

4. Neoplastic progression and evolution prognosis

5. Melanocytoma differentiation

6. Melanocytoma progression

7. Melanocytoma proliferation and apoptosis

8. Melanocytoma-associated angiogenesis

9. Conclusion

Correspondence to: Professor G.E. Piérard, Department of Dermatopathology, CHU Sart Tilman, B-4000 Liège, Belgium E-mail: gerald.pierard@ulg.ac.be

Key words: melanoma, melanocytoma, prognostic factor, risk stratification, Spitzoid tumor

\section{Introduction}

One major expectation of patients and clinicians is to make a clear-cut distinction between benign and malignant melanocytic neoplasms. This can be reached for the vast majority of such lesions. In particular, the histological diagnosis of cutaneous melanoma is often straightforward (1). However, the situation is somewhat more ambiguous and controversial for other atypical melanocytic neoplasms. Historically, the problem was probably first raised a century ago when Darier and Civatte described, in some detail, an unusual melanocytic tumor developing rapidly on the nose of a young child, and were unable to decipher whether the lesion was benign or malignant (2). At present, one can question whether dermatopathologists have made much progress in resolving this conundrum because of the inability to accurately interpret such melanocytic lesions histologically and to rate their biological potential (3).

For these unusual melanocytic neoplasms, the current histological criteria for whether they are benign or malignant are not completely met, or fail to make the distinction between benign and malignant neoplasms with confidence $(4,5)$. Some of them may enter a spectrum going from benign to not-sobenign, not-so-malignant and malignant. Experienced pathologists commonly recognize the important microscopical features, but they may disagree with the interpretation and diagnosis (6-8).

There appears to be a trend in the literature to diagnose Spitz nevus for any problematic, probably benign, cellular junctional or compound nevus $(3,9)$. In previous decades, the recognition of Spitz naevus variants has resulted in a marked expansion of its clinical and histological spectrum. This may risk dilution of the criteria for diagnosis of the regular Spitz nevus, which should probably remain a distinct and recognizable entity. Another trend showed that the intermediate categories between common naevi and melanomas have received various designations including among others melanocytoma, melanocytic dysplasia, deep penetrating naevus, minimal deviation and borderline melanoma, intermediate melanocytic tumor, melanocytic tumor of uncertain malignant potential (MELTUMP), spitzoid melanocytic tumor of uncertain malignant potential (STUMP), malignant Spitz naevus, metastasizing and atypical Spitz tumor, and spitzoid lesion $(3,4,9-16)$. The profusion of all these terms may appear quite confusing. In the present review, they are grouped under the heading melanocytoma. 


\section{Definition of melanocytoma}

Although histology is the mainstay for diagnosing atypical melanocytic neoplasms, clinical features are also of central importance and should therefore never be disregarded. Melanocytoma can be used as a single term to encompass melanocytic neoplasms which do not meet the classical histological criteria of any type of common melanocytic naevi and cutaneous melanoma (4). Melanocytoma in its strict etymological sense, implies a benign tumor of melanocytes (10). This term was initially selected to clearly separate the Spitz and pigmented spindle cell tumors (Reed naevus) from melanocytic naevi (10). This concept was further extended to a series of other atypical melanocytic lesions (4). The possible association with pregnancy and the administration of growth hormones in children of short stature has also been shown $(17,18)$.

Melanocytomas often develop singly. Occasionally, multiple melanocytomas occur. Some of these lie grouped together (agminate type) and may arise after the removal of a solitary lesion (19).

The melanocytoma class is histologically recognized by combining certain of the following criteria: architectural abnormalities including disordered groupments of melanocytic nests, possible asymmetry, discrete nuclear atypia, anisokaryocytosis and the possible juxtaposition of an ancillary focal or diffuse inflammatory cell reaction. However, the variable combination of these signs in different lesions precludes any straightforward set of major criteria that can be used to confidently identify distinguishable subsets of melanocytomas, with the exception of the common type of Spitz melanocytoma.

Another special type of melanocytoma presents as an atypical dermal nodule in an otherwise normal-looking melanocytic naevus $(3,17,20,21)$. Such atypical nodules may suggest an intralesional transformation, which some pathologists regard as a sign of malignancy, although it does not exhibit other features of aggressive behaviour. The increase in size of this type of melanocytic lesion is mainly due to more abundant, pale cytoplasm in each individual cell. The nuclei show only a marginal increase in size and do not exhibit pleomorphism. There may be invagination of the nucleus by cytoplasm, giving a vacuolated appearance. Mitoses are hardly ever seen.

In our experience, the overall melanocytoma $\mathrm{F}$ and $\mathrm{M}$ gender ratio was 1.6 (Table I). The age distribution was similar in the two gender groups. In general, the majority of Spitz tumors occur under the age of 20 years (3). In contrast, the incidence of all melanocytomas combined peaked in our series during the 3rd and 4th decade of life (Table I). A sharp decrease was found after the age of 50 years. Such age and gender distribution resembles what we reported for malignant melanomas $(22,23)$.

\section{Uncertainties about melanocytomas}

The dichotomy between melanocytomas and malignant melanomas presupposes that all members of each group are either completely benign or fully malignant. This concept probably does not hold true. The variability in the histological
Table I. Age and gender distribution of 425 melanocytomas.

\begin{tabular}{lrr}
\hline Age (years) & F & M \\
\hline $0-10$ & 17 & 15 \\
$11-20$ & 28 & 23 \\
$21-30$ & 70 & 46 \\
$31-40$ & 86 & 30 \\
$41-50$ & 43 & 28 \\
$51-60$ & 10 & 8 \\
$61-70$ & 4 & 7 \\
$71-80$ & 2 & 3 \\
$81-90$ & 1 & 2 \\
$91-100$ & 1 & 1 \\
\hline Total & 262 & 163 \\
\hline
\end{tabular}

presentations of melanocytomas poses diagnostic difficulties, particularly in the distinction with malignant melanomas $(4,7,24,25)$. The clinical attributes may also be disturbing. Distinguishing between cutaneous melanoma, including its unusual variants masquerading as other entities and, benign lesions mimicking melanoma is one of the thorniest diagnostic conundrums for the dermatologist and the dermatopathologist (Fig. 1). Any error in this differential diagnosis has profound consequences including mutilating overtreatment or, conversely, life-threatening under-treatment. At the present time, controversies exist as to the diagnoses to be given for certain neoplasms and their predictive evolution. As a result, there is also potential implication in legal liability.

While a consensus clearly exists regarding the inadequacy of existing clinicopathological classifications and the need for additional research in this area, the empirical impressions and opinions of researchers, dermatopathologists and clinicians as to the nosology of several types of melanocytomas appear to vary widely. Even the definition of malignancy is disputed in the field of melanocytic neoplasms. There may be melanocytic neoplasms, particularly with a spitzoid aspect, that do not remain confined to the primary site. They exhibit the propensity to spread regionally in the skin (agminate type) and in the lymph nodes, but not to more distant sites. The interpretation of regional spread is subject to controversy. Certain authors regard it as formal proof of malignancy and consider the secondary lesions as satellitosis or in-transit metastases. Others argue that this stance constitutes an over-interpretation. Nonetheless, it appears that the regional cutaneous and nodal spread of melanocytomas neither equals distant metastasis nor constitutes sufficient proof of malignancy.

\section{Neoplastic progression and evolution prognosis}

In the context of melanocytic neoplasms, ample evidence exists of pathological, molecular and genetic aspects correlated with a gradation from benign naevi, through dysplasia and melanoma in situ, to invasive melanoma. This occurs firstly without metastatic potential and then with a nodular or 
Table II. Primary antibodies.

\begin{tabular}{lllll}
\hline Clone/ascitis & \multicolumn{1}{c}{ Antigen } & Type and isotype & Dilution & Source \\
\hline S100 a, b & S100 a, b & Pab & Prediluted & Dakopatts \\
A103 & Melan-A/Mart-1 & Mab, IgG1 & $1: 10$ & Novocastra \\
HMB45 & HMB45, gp100 & Mab, IgG1, $\kappa$ & $1: 350$ & Dakopatts \\
CD63 & NKI-C3 & Mab, IgG1 & Prediluted & PM biomedicals \\
T311 & Tyrosinase & Mab, IgG2a & $1: 25$ & Novocastra \\
MIB-1 & Ki-67 & Mab, IgG1 & Prediluted & Immunotech \\
Ulex europaeus & Ulex europaeus lectin & Pab & Prediluted & Dakopatts \\
\hline
\end{tabular}

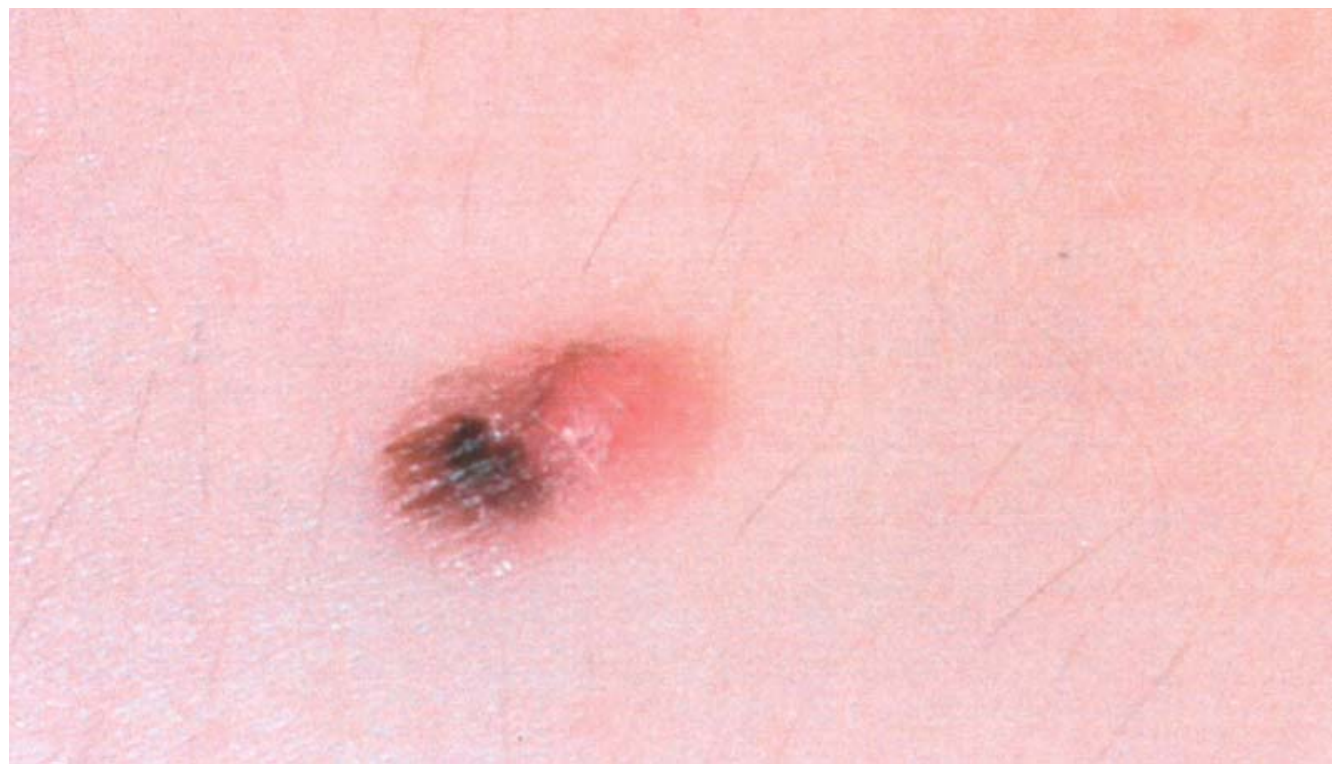

Figure 1. Melanocytoma of a nipple clinically mimicking a malignant melanoma of the nodular type.

vertical growth phase capable of metastasis (26-29). Despite these facts, and from clinical and histological standpoints, malignant melanoma is not one predictable disease, but exhibits a variety of different evolutive patterns. For instance, cutaneous melanoma may develop, spread widely and kill in a matter of months. However, it may remain silent in a growthstunted phase or slowly progress for many years (30). It may also present as a smouldering disease or remain confined to a body area throughout its course. Thus, the diagnosis is often made by microscopic evaluation without, however, predicting the clinical course under the microscope with certainty. This is particularly true when dealing with the initial undistinctive stages of the malignant process. Many histological criteria have to be integrated to reach any diagnosis with confidence, but no one criterion of malignancy is absolute and can predict the evolution and outcome of the disease with certainty.

Any inflammatory infiltrate, when present, is distributed evenly throughout melanocytomas, although it may be slightly more marked at the basal and lateral sides. The presence of plasma cells highlighted by CD138 immunoreactivity should prompt a critical reconsideration of the diagnosis of melanocytoma. Similarly, signs of neoplastic regression as commonly seen in malignant melanomas are almost never encountered in melanocytomas.
Once the diagnosis of melanocytoma has been made, the question deals with the correlation of the prognosis. Immunohistochemistry remains the most common and efficient method in diagnostic and prognostic pathology. Immunohistochemical markers of melanocytic lesions have potential diagnostic and prognostic value. Unfortunately, they may bring supportive and controversial information $(4,31,32)$. In the field of melanocytomas, four main categories of antibodies can be used for immunohistochemistry and prove to be more useful in determining their biological status (4). Our laboratory is currently using the panel displayed in Table II. The first category of immunohistological markers encompasses differentiation antibodies primarily helping in the identification of the neoplastic cell lineage and any heterogeneity in the cell characteristics. Typical antibodies of this group are directed to the $\mathrm{S} 100$ protein, the melanoma antigen recognized by T cells (Mart-1 and melan-A), as well as tyrosinase and its related Mel 5 protein (33). The second set of antibodies corresponds to putative neoplastic progression markers. These antibodies target gp100-HMB45 and CD63. Factor XIIIa, present in peritumoral and intratumoral dermal dendrocytes can also be investigated (34), as well as the immunohistochemical pattern of the basement membrane components (35). The third set comprises of the proliferation 
MIB-1/Ki-67 marker as well as a set of antibodies exploring neoplastic apoptosis. The fourth set of antibodies encompasses Ulex europaeus agglutinin-1 and any other endothelial cell marker which assesses the neoplastic-related angiogenesis.

\section{Melanocytoma differentiation}

In general, common benign melanocytic tumors are structured in an orderly manner showing symmetry and so-called maturation with a deeper location of smaller cells inside the dermis. The immunohistochemical revelation of the differentiation markers including S100 protein and melan-A appears quite diffuse and uniform in these lesions and in most melanocytomas (4). Tyrosinase immunoreactivity decreases toward the base of most melanocytomas. In contrast, lateral asymmetry and patchy patterns of immunohistochemical differentiation are typically found in cutaneous melanomas and in some MELTUMP and STUMP as well (35).

\section{Melanocytoma progression}

The neoplastic progression of melanocytomas may be complex because it depends on the combination of many biological factors. Distinct profiles of molecular expressions are expected during melanocytoma progression. HMB-45 and CD63 are commonly negative in benign melanocytic nevi, but may show some immunoreactivity in triggered lesions. In melanocytomas, the pattern of positivity is characteristically superficial in location $(3,4,31,36)$. The two markers are quite often expressed in combination in melanocytomas including MELTUMP and STUMP.

\section{Melanocytoma proliferation and apoptosis}

The mitotic index of the dermal component is one of the most important parameters for evaluating melanocytic lesions as increasing proliferative rates appear to correlate with the likelihood of aggressive behaviour or malignancy (37-43). Furthermore, these parameters are quantifiable. Mitoses observed in the deepest parts of the melanocytic neoplasm appear to have greater significance than more superficially located mitoses. There are no absolute thresholds for the proliferative indexes being indicative of malignancy. However, a brisk mitotic rate or Ki-67 index is not a common feature of melanocytomas, but rather suggests a malignant melanoma. In addition, the presence of abnormal mitotic figures is often indicative of malignancy. In the vast majority of melanocytomas, the mitotic index is $<6 / \mathrm{mm}^{2}$ and the $\mathrm{Ki}-67$ index is $<5-10 \%$. Higher values should prompt the revision of the diagnosis. The quantitative loss of Ki-67 expression with depth correlates with maturation and less atypical lesions (3).

Apoptosis is quite different from necrotic cell death and represents one major mechanism involved in reducing the expansile growth of melanocytic neoplasms. Melanocytic cells can undergo apoptosis resulting from the balance between the pro-apoptotic and anti-apoptotic (pro-survival) regulators. The process can be regarded as a programmed cell death which is recognized by a distinct set of morphological, biochemical and immunochemical alterations. Apoptosis is characterized biochemically by DNA fragmentation into oligonucleosome-sized fragments. It is recognized morphologically by cell shrinking, chromatin condensation and the formation of apoptotic bodies with well preserved internal and external membranes. In most instances, apoptotic bodies are rapidly phagocytosed by adjacent cells or macrophages (33). The regulation of apoptosis not only involves a complex interaction of extracellular signals, but also the intrinsic sensitivity of a cell towards the induction of apoptosis which can be up- or down-regulated by a number of gene products.

As a functional counterpart of mitosis, apoptosis plays a crucial role in tissue homeostasis and is normally firmly regulated. Apoptosis is deranged in melanocytic neoplasms when the components and regulators of the cellular apoptotic machinery are mutated or present in inappropriate amounts (44). The pro-apoptotic factors include Bax, Bid, Fas/FasL, IFN, c-Kit/SCF, Noxa, p53, PITSLRE, PUMA, TNF and TRAIL (45). The anti-apoptotic factors include Bcl-2, Bcl-XI, livin, Mcl-1, ML-LAP, NFאB and survivin. Alternatively, other molecules including endothelins, integrins, c-Myc and TRAF-2 may show either pro- or anti-apoptotic effects (40).

\section{Melanocytoma-associated angiogenesis}

Microvessels have been reported to be fewer in melanocytomas than in malignant melanomas. Using antibodies to CD31 and Ulex europaeus agglutinin allows for a better assessment of the neoplastic vascularization $(46,47)$. The vascular endothelial growth factor (VEGF) is frequently detectable in malignant melanomas, contrasting with the usual negativity in melanocytomas (48).

The extent of angiogenesis may help in distinguishing melanocytomas from malignant melanomas (49). However, it should be noted that some growth-stunted malignant melanomas show weak angiogenesis (30). Conversely, angiomatoid melanocytomas have been described (50).

\section{Conclusion}

There is increasing evidence that melanocytomas (atypical Spitz tumor, MELTUMP and STUMP) represent a type of melanocytic neoplasm distinct from common melanocytic naevi and malignant melanomas. This concept has found general acceptance. It brings greater agreement between dermatopathologists and clinicians and it supports a clearer understanding for the benefit of the patients. It remains that the distinction between atypical but benign melanocytic neoplasms and malignant melanoma may prove to be difficult and even practically impossible in certain instances. The discrimination between these neoplasms is subject to substantial interobserver variation. Thus, the interpretations of the observations are complex and may remain inconclusive. As a consequence, the terms melanocytoma, atypical Spitz tumor or MELTUMP and STUMP are now used for lesions somewhat resembling Spitz tumor, but with additionally worrying features. The use of the melanocytoma concept makes a diagnosis out of what is essentially a statement of uncertainty. Nevertheless, there is a group of lesions for which the current histological criteria of melanocytoma and of melanoma do not permit a confident and unequivocal diagnosis. Based on our experience, immunohistochemistry 
improves the distinction between melanocytomas and melanomas more than other additional techniques. Although the data are in need of independent confirmation, there is reason to hope that some of the parameters put forward will prove to be robust and applicable in a routine diagnostic setting.

Much remains to be learned about melanocytomas. Further study of the melanocytoma spectrum by means of various additional techniques holds promise for a gradual increase in diagnostic accuracy in the future. Detailed and precise longterm follow-up of regional and distant metastasis and of neoplasm-related death must remain the mainstay of definitive classification and of the corroboration of diagnostic applicability of any offered diagnostic clue or parameter.

\section{Acknowledgements}

This work was supported by a grant from the 'Fonds d'Investissement de la Recherche Scientifique' of the University Hospital of Liège. No other sources of funding were used to assist in the preparation of this manuscript.

\section{References}

1. Smoller BR: Histologic criteria for diagnosing primary cutaneous malignant melanoma. Modern Pathol 19: 34-40, 2006.

2. Darier J and Civatte A: Naevus ou naevo-carcinome chez un nourisson. Bull Soc Franc Derm Syph 21: 61-63, 1910.

3. Barnhill RL: The spitzoid lesion: rethinking Spitz tumors, atypical variants, 'spitzoid melanoma' and risk assessment. Modern Pathol 19: S21-S33, 2006.

4. Quatresooz P, Arrese JE, Piérard-Franchimont C and Piérard GE: Immunohistochemical aid at risk stratification of melanocytic neoplasms. Int J Oncol 24: 211-216, 2004.

5. Moi WJ and Krausz T: Spitz nevus versus spitzoid melanoma. Diagnostic difficulties, conceptual controversies. Adv Anat Pathol 13: 147-156, 2006.

6. Farmer ER and Gonin R: Discordance in the histopathologic diagnosis of melanoma and melanocytic nevi between expert pathologists. Hum Pathol 27: 528-531, 1996.

7. Grant-Kels JM, Bason ET and Grin CM: The misdiagnosis of malignant melanoma. J Am Acad Dermatol 4 : 539-548, 1999.

8. Brochez L, Verhaeghe E, Grosshans E, et al: Inter-observer variation in the histopathological diagnosis of clinically suspicious pigmented skin lesions. J Pathol 196: 459-466, 2002.

9. Cook MG: Diagnostic pitfalls with melanocytic tumours. Curr Diagn Pathol 10: 463-472, 2004.

10. Ainsworth AM, Folberg R, Reed RJ and Clark WH: Melanocytic Nevi, Melanocytomas, Melanocytic Dysplasias and Uncommon Forms of Melanoma. In: Human Malignant Melanoma: Clinical Oncology Monographs. Clark WH, Goldman KI and Mastrangelo MJ (eds). Grune \& Stratton, New York, pp167-208, 1979.

11. Reed RJ: Minimal deviation melanoma. Hum Pathol 21: 1206-1211, 1990.

12. Barnhill RL, Flotte TJ, Fleischli M and Perez-Atayde A: Cutaneous melanoma and atypical Spitz tumors in childhood. Cancer 76: 1833-1845, 1995.

13. Reed RJ: Dimensionalities: Bordeline and intermediate melanocytic neoplasia. Hum Pathol 30: 521-524, 1999.

14. Gurbuz Y, Apaydin R, Muezzinoglu B and Buyukbabani N: A case report and a current dilemma in histopathology: atypical Spitz nevus or spitzoid melanoma. Pediatr Dermatol 19: 99-102, 2002.

15. Mones JM and Ackerman AB: 'Atypical' Spitz's nevus, 'malignant' Spitz's nevus, and 'metastasizing' Spitz's nevus: A critique in historical perspective of three concepts flawed fatally. Am J Dermatopathol 26: 310-333, 2004.

16. Lee JB: Spitz nevus versus melanoma: limitation of the diagnostic methodology exposed. Eur J Dermatol 16: 223-224, 2006.

17. Piérard GE, Piérard-Franchimont C, Nikkels AF, et al: Naevocyte triggering by recombinant human growth hormone. $\mathrm{J}$ Pathol 180: 74-79, 1996.
18. Onsun N, Saracoglu S, Demirkesen C, et al: Eruptive widespread Spitz nevi: can pregnancy be a stimulating factor? J Am Acad Dermatol 40: 866-867, 1999.

19. Sabroe RA, Vaingankar NV, Rigby HS and Peachey RD: Agminate Spitz naevi occurring in an adult after the excision of a solitary Spitz naevus: Report of a case and review of the literature. Clin Exp Dermatol 21: 197-200, 1996.

20. Ball NJ and Golitz LE: Melanocytic naevi with focal atypical epithelioid cell components: a review of seventy-three cases. J Am Acad Dermatol 40: 724-729, 1994.

21. Collina G, Deen S, Cliff S, et al: Atypical dermal nodules in benign melanocytic naevi. Histopathology 31: 97-101, 1997.

22. Quatresooz P, Uhoda I, Fumal I, et al: Revisiting the genderlinked melanoma burden. Dermatology 209: 197-201, 2004.

23. Uhoda I, Quatresooz P, Fumal I, et al: Updating trends in cutaneous cancers in south-east Belgium. Oncol Rep 12: 111-114, 2004.

24. Orchard DC, Dowling JP and Kelly JW: Spitz naevi misdiagnosed histologically as melanoma: prevalence and clinical profile. Aust J Dermatol 38: 12-14, 1997.

25. Barnhill RL, Argenyi ZB, From L, et al: Atypical Spitz nevi/ tumors: lack of consensus for diagnosis, discrimination from melanoma, and prediction of outcome. Hum Pathol 30: 513-520, 1999.

26. Alonso SR, Ortiz P, Pollan M, et al: Progression in cutaneous malignant melanoma is associated with distinct expression profiles. A tissue microarray-based study. Am J Pathol 164: 193-203, 2004.

27. Coulson A, Ross JS, Slominski A, et al: Molecular diagnostics in melanoma. J Am Acad Dermatol 52: 743-775, 2005.

28. Claessens N, Piérard GE, Piérard-Franchimont C, et al: Immunohistochemical detection of incipient melanoma micrometastases. Relationship with sentinel lymph node involvement. Melanoma Res 15: 107-110, 2005.

29. Crowson N, Magro CM and Mihm MC: Prognosticators of melanoma, the melanoma report, and the sentinel lymph node. Modern Pathol 10: S71-S87, 2006.

30. Piérard-Franchimont C, Henry F, Heymans O and Piérard GE: Vascular retardation in dormant growth-stunted malignant melanomas. Int J Mol Med 4: 403-406, 1999.

31. Kanter-Lewensohn L, Hedblad MA, Wejde J and Llqarsson O: Immunohistochemical markers for distinguishing Spitz nevi from malignant melanomas. Mod Pathol 10: 917-920, 1997.

32. Mangini J, Li N and Bhawan J: Immunohistochemical markers of melanocytic lesions. A review of their diagnostic usefulness. Am J Dermatopathol 24: 270-281, 2002.

33. Piérard-Franchimont C, Letawe C, Nikkels AF and Piérard GE: Patterns of the immunohistochemical expression of melanocytedifferentiation antigens and density of CD45R $0^{+} \mathrm{T}$ lymphocytes and L1-protein + macrophages in primary cutaneous melanomas. Int J Mol Med 2: 721-724, 1998.

34. Piérard-Franchimont C, Arrese JE, Nikkels AF, et al: Factor XIIIa-positive dermal dendrocytes and proliferative activity of cutaneous cancers. Virchows Arch 429: 43-48, 1996.

35. Quatresooz P and Piérard GE: Immunohistochemical investigation of $\alpha 1$ (IV) and $\alpha 5$ (IV) collagen chains in a broad spectrum of melanocytic tumours. Melanoma Res 15: 161-168, 2005.

36. Bergman R, Dromi R, Trau H, et al: The pattern of HMB-45 antibody staining in compound Spitz nevi. Am J Dermatopathol 17: 542-546, 1995.

37. Piérard GE, Piérard-Franchimont C, Henry C and Lapière M: The proliferative activity of cells of malignant melanomas. Am J Dermatopathol 6: S317-S324, 1984.

38. Spatz A, Calonje E, Handfield-Johnes S, et al: Spitz tumors in children: a grading system for risk stratification. Arch Dermatol 135: 282-285, 1999.

39. Walsh N, Crotty K, Palmer A, et al: Spitz nevus versus spitzoid malignant melanoma: An evaluation of the current distinguishing histopathologic criteria. Hum Pathol 29: 1105-1112, 1998.

40. Li LX, Crotty KA, McCarthy SW, et al: A zonal comparison of MIB 1-Ki67 immunoreactivity in benign and malignant melanocytic lesions. Am J Dermatopathol 22: 489-495, 2000.

41. Bergman R, Malkin L, Sabo E, et al: MIB-1 monoclonal antibody to determine proliferative activity of Ki-67 antigen as an adjunct to histopathologic differential diagnosis of Spitz nevi. J Am Acad Dermatol 44: 500-504, 2001.

42. Vollmer RT: Use of Bayes rule and MIB-1 proliferation index to discriminate Spitz nevus from malignant melanoma. Am J Clin Pathol 122: 499-505, 2004.

43. Kapor P, Selim MA, Roy LC, et al: Spitz nevi and atypical Spitz nevi/tumors: a histologic and immunohistochemical analysis. Mod Pathol 18: 197-204, 2005. 
44. Sprecher E, Bergman R, Meilick A, et al: Apoptosis, Fas and Fas-ligand expression in melanocytic tumors. J Cutan Pathol 26: 72-77, 1999.

45. Hussein M, Haemel A and Wood ES: Apoptosis and melanoma: molecular mechanisms. J Pathol 199: 275-288, 2003.

46. Piérard GE and Piérard-Franchimont C: Stochastic relationship between the growth fraction and vascularity of thin malignant melanomas. Eur J Cancer 33: 1888-1892, 1997.

47. Heymans O, Blacher S, Brouers F and Piérard GE: Fractal quantification of the microvasculature heterogeneity in cutaneous melanoma. Dermatology 198: 212-217, 1999.
48. Bayer-Garner IB, Hough AJ and Smoller BR: Vascular endothelial growth factor expression in malignant melanoma: prognostic versus diagnostic usefulness. Mod Pathol 12: 770-774, 1999.

49. Cockerell CJ, Sonnier G, Kelly L and Patel S: Comparative analysis of neovascularization in primary cutaneous melanoma and Spitz nevus. Am J Dermatopathol 16: 9-13, 1994.

50. Diaz-Cascajo C, Borghi S and Weyers W: Angiomatoid Spitz nevus: a distinct variant of desmoplastic Spitz nevus with prominent vasculature. Am J Dermatopathol 22: 135-139, 2000. 